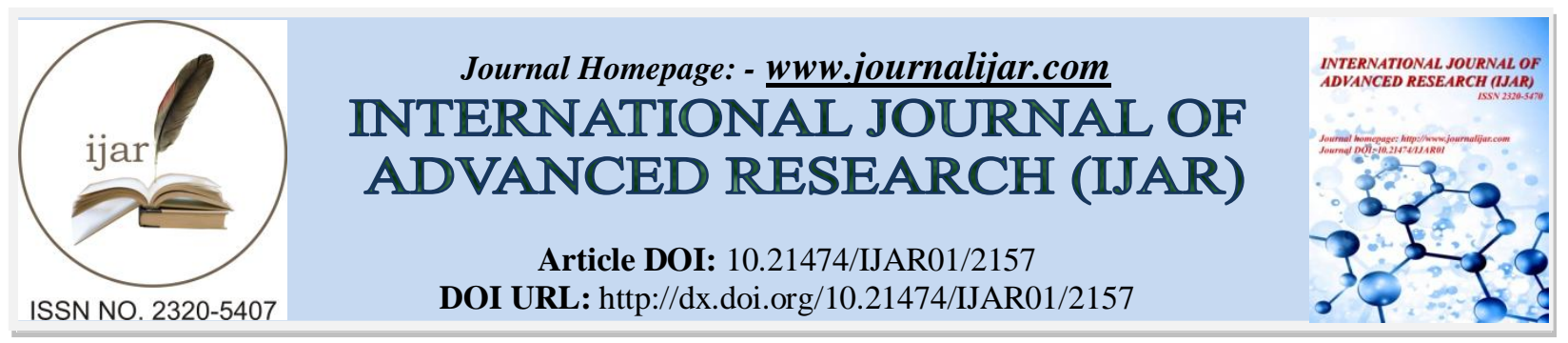

RESEARCH ARTICLE

\title{
PARIS POLYPHYLLA SMITH: AN IMPORTANT HIGH VALUE HIMALAYAN MEDICINAL HERB
}

\author{
Mohd Tariq ${ }^{* 1}$, Shilpi Paul ${ }^{1}$, I.D. Bhatt ${ }^{1}$, K.Chandrasekar ${ }^{1}$, Veena Pande ${ }^{2}$ and S.K.Nandi ${ }^{1}$. \\ 1. G.B. Pant National Institute of Himalayan Environment and Sustainable Development, Kosi-Katarmal, Almora- \\ 263 643, Uttarakhand, India. \\ 2. Department of Biotechnology, Kumaun University, Bhimtal Campus, Bhimtal- 263 136, Uttarakhand, India.
}

\section{Manuscript Info}

Manuscript History

Received: 26 September 2016

Final Accepted: 29 October 2016

Published: November 2016

Key words:-

Diosgenin, Ecological Niche Modelling,

Paris polyphylla, Propagation.

\section{Abstract}

Paris polyphylla Smith has drawn much attention in recent years as used in traditional system of medicine since ancient times, one of the important medicinal herbs used in homeostasis, antimicrobial and anti-inflammatory infections. The excessive extraction of this species for use in the pharmaceutical industry has resulted in the ruthless destruction of natural populations. Therefore, attempt needs to be taken to adopt urgent conservation steps and develop innovative methods to propagate and cultivate this economically important and high value medicinal herb of Indian Himalayan Region (IHR). This study provides information on its medicinal properties, development made so far, and some gaps that are lacking.

Copy Right, IJAR, 2016,. All rights reserved.

\section{Introduction:-}

Paris polyphylla Sm. (Family: Melanthiaceae; Hindi name: Satuwa) has drawn much attention in the recent past as it is an important folk medicinal herb and a source of various bioactive compounds. The rhizomes of the species are widely used as an antihelmintic, antispasmodic, digestive stomachic, expectorant and vermifuge (IUCN, 2004; Bhattarai et al. 2006). P. polyphylla has gained much attention due to the presence of steroidal saponins (in the rhizomes) which are known for their enormous medicinal properties such as antitumor (Wu et al. 2004; Lee et al 2005; Sun et al. 2007, Man et al. 2009), antifungal (Deng et al. 2008), antihelmintic (Devkota et al. 2007; Wang et al. 2010) and inhibitory activities against abnormal uterine bleeding (Fu et al. 2008). It is harvested mainly from the natural population and thus the frequency in nature is gradually decreasing. The national and international demands of the species are very high and sold at Rs. 4500/- per kg (1US\$=Rs. 68.00) dry weight and Rs. 1500/- per kg fresh weight; its high trade value and rampant illegal extraction has placed it in the Endangered category (CAMP, 2003).

The mixture of roots and rhizomes of this species is reported to be used in treating poisonous snakebites, insect bites, and boils. The genus Paris comprises of 24 species of perennial herbs distributed throughout Europe, Eastern Asia and the Himalayan region. It is also found to grow in Bhutan, Nepal and India; in India, it has been reported from Uttarakhand, Manipur and Himachal Pradesh. P. polyphylla is native to Southwest of China, Yunnan province (Li H, 1984). The term 'Paris' is derived from the word 'pars' which means symmetry of plant and multiples of four in which its foliage, flowers and fruits grow. The plant is an annual herb, upto $60 \mathrm{~cm}$ in height, stem stout, rhizome creeping and segmented; flowers solitary, terminal, greenish at the apex, subtended by 4-9 lanceolate long-pointed leaf-like bracts. It grows at an altitudinal range of 1000-3200m asl (Rawat et al. 2010) in the undergrowth of forest, bamboo thickets and also in grassy or rocky slopes. It grows well in soil with pH ranging from 5.6-7.5, i.e. in slightly acidic to neutral soils. The plant prefers light (sandy) and medium (loamy) soil and can grow well in full 
shade (deep woodlands). The plant requires moist humus-rich soil and therefore, regular watering is essential (Grey, 1938; Philips and Rix, 1989; Huxley 1992; Thomas, 1990).

This study describes various aspects related to in vitro multiplication, pharmacology and recent biotechnological methods adopted for conservation of this species. Since emphasis on propagation and conservation strategies needs to be framed using various biotechnological and ecological methods (ENM), hence information on furthering research in IHR would be considered essential to suggest conservation strategies for this threatened species. Due to high demand for medicinal purposes, the population of this species has decreased substantially. A study from Eastern Himalaya shows that low density of population ranged between 0.4 to 1.48 individuals $\mathrm{m}^{-2}$ (Paul et al. 2015). Further population status of species from Western Himalaya is not known. Hence, future studies need to focus on assessment of populations in the wild.

\section{Phytoconstituents and pharmacological activity:-}

Steroidal saponins are the major chemical constituents of genus Paris. Among them Diosgenin, a terpenoid and precursor of various synthetic drugs that are extensively used in the pharmaceutical industry, is a most frequent representative (Wei et al. 2014). These steroidal saponins are generally present in the rhizome. The main compounds identified include Przewalskinone B (1, 5-Dihydroxy-7-methoxy-3-methylanthraquinone) which has an anthraquinone skeleton, and Polyphyllin C (Diosgenin-3-O [ $\alpha-\mathrm{L}$ rhamnopyanosyl (1-3)- $\beta$-D-glucopyranoside) and Polyphyllin D (Diosgenin-3-O [ $\alpha$-L-rhamnopyanosyl (1Rha-2Glu)- $\alpha$-L-arabinofuranosyl (1Ara- 4Glu)]- $\beta$-DGlucopyranoside) also possessing steroidal skeleton. Further, saponin-1 (Diosgenin-3-O [ $\alpha$-L-rhamnopyanosyl (1Rha-2Glu)- $\alpha$-L-rhamnopyranosyl (1Ara_4Glu)]- $\beta$ - D-Glucopyranoside), Stigmasterol and Stigmasterol-3O- $\beta$-D-glucoside have been isolated from P. polyphylla (Devkota, 2005). Eight known steroids were also reported to be isolated from the rhizomes (Wang et al. 2007). Chemically, some other important glucosides that possesses high trade value and important constituent for pharmaceutical formulation, namely Diosgenin Saponin A (composed of diosgenin, glucose and rhamnase), Saponin B (pariphyllin), Saponin C (diosgenin -3-O- $\alpha-\mathrm{L}-$ rhamnopyranosyl (1-4) $\beta$-D-glucopyranoside), Polyphyllins, etc. have also been isolated from rhizomes of P. polyphylla (Rastogi \& Mehrotra, 1993).

Steroidal saponins of $P$. polyphylla i.e., Polyphyllin D could serve as an agent for breast cancer treatment (Lee et al., 2005). It was found that treatment of MCF-7 and MDA-MB-231 cells with Polyphyllin D resulted in the inhibition of viability and induction of apoptosis in a dose dependent manner. Mechanistically, Polyphyllin D dissipates the mitochondrial membrane potential, induces a down regulation of anti-apoptotic Bcl-2 expression (apoptosis regulating protein) and an up regulation of pro-apoptotic Bax-expression and activate caspase 9; this further suggest that saponins of this species may be potentially used as an anticancer agent against human breast cancer.

The bioactive natural products from the rhizome of $P$. polyphylla, i.e., polyphyllin D, polyphyllin C and Saponin -I showed mild to moderate anti-leishmanial activities (Devkota et al., 2005). Moreover, roots also exhibited antibacterial action against Bacillus dysenteriae, Bacillus paratyphi, Escherichia coli, Staphylococcus aureas, Haemolytic streptococci, Meningococci and some other bacteria (Anonymous, 2002). Further research is needed to screen out the phytochemical compounds responsible for the pharmacological activities of this herb. The phytochemical bioactive compounds of $P$. polyphylla and their derivatives can therefore be used as a potential source for the discovery of new drugs.

\section{Diosgenin: synthesis:-}

Diosgenin is a naturally occurring steroid also present in P. polyphylla and is known to suppress fatty acid synthase expression in over expressing breast cancer. It has the potential to advance as chemo-preventive and chemotherapeutic agents for cancers. Structurally, it is similar to cholesterol and other steroids (Figure 1a). Since its discovery, diosgenin is the single main precursor in the manufacture of synthetic steroids in the pharmaceutical industry (Djerassi et al., 1952). Structurally, diosgenin [(25R)-spirost-5-en-3b-ol] is a spirostanol saponin consisting of a hydrophilic sugar moiety linked to a hydrophobic steroid aglycone (Figure 1b). Although, mevalonic acid (MVA) and isopentenyl diphosphate (IPP) pathway have been well studied however, the synthesis of Diosgenin starting from squalene synthase is still not very clear (Figure 2). Limited studies have been reported in the area of pathway identification of diosgenin synthesis. It would be important to find out the key genes and enzymes that regulate the biogenesis of diosgenin, thus helping in pathway engineering, and subsequently enhancing the in vitro 
production of pharmaceutically and potentially bioactive compounds of this important herb. Therefore, there is a need to take up further studies on diosgenin biosynthesis pathway.

a

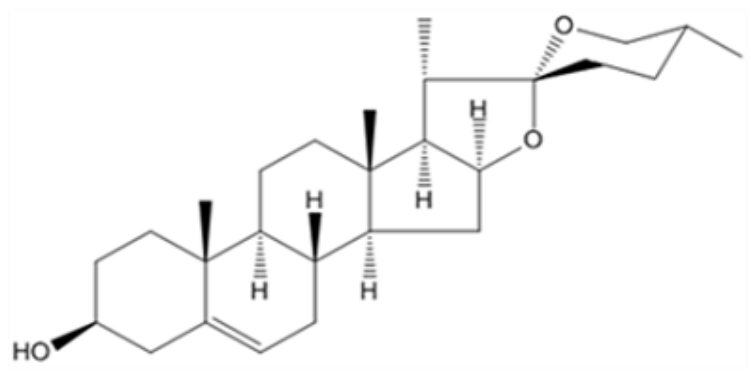

b

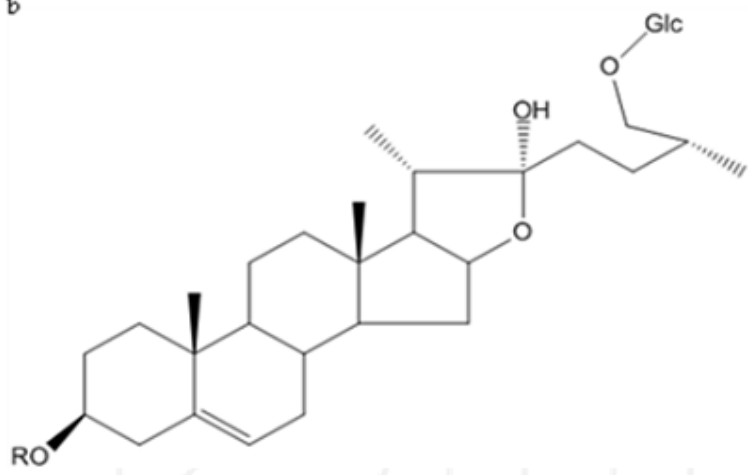

Fig.1:- Structure of Diosgenin analogue protodioscin (a), and a steroid saponins consisting of a hydrophilic sugar moiety linked to a hydrophobic steroid aglycone (b)

\section{Cytosol}

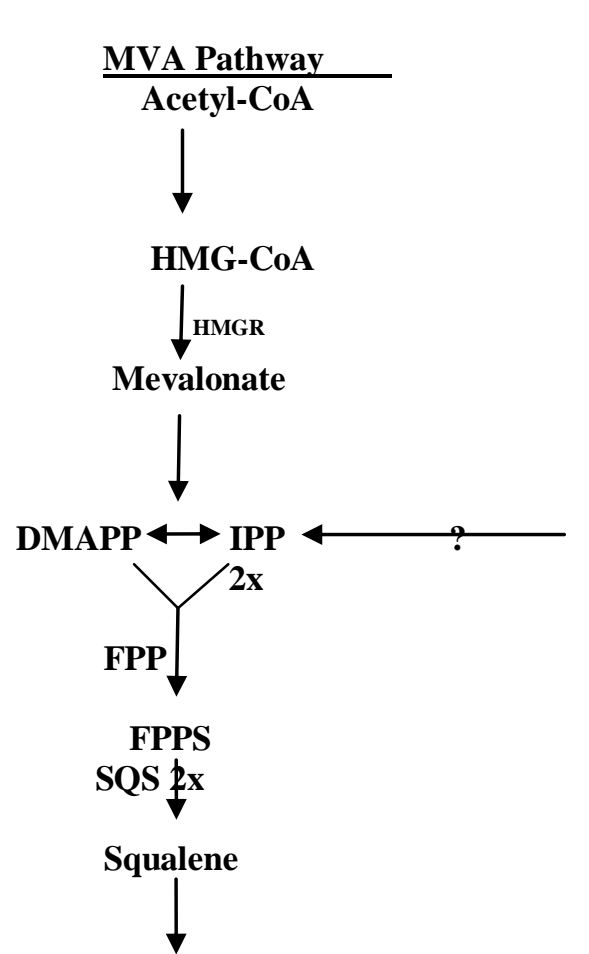

Plastid

Pyruvate+GA-3-P
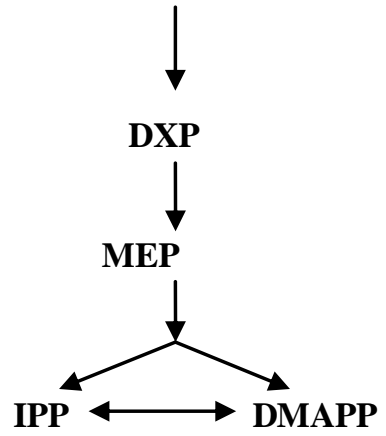

MEP Pathway

\section{2, 3- Epoxysqualene}

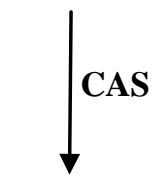

Cycloartenol $\longrightarrow$ Diosgenin

Fig 2:- The biosynthesis pathway and structure of diosgenin.

MVA: - mevalonic acid; GA-3-P: - glyceraldehyde-3-phosphate: DXP: - 1-deoxy-D-xylulose-5-phosphate: MEP: 2-C-methyl-D-erythritol-4-phosphate; HMG-CoA: - 3-hydroxy-3-methylglutaryl-CoA; HMGR: -3-hydroxy-3methylglutaryl-CoA reductase; IPP: - Isopentenyl diphosphate; DMAPP: - dimethylallyl diphosphate; FPP: farnesyl diphosphate; FPPS:- FPP synthase; SQS: -Squalene synthase; CAS: - Cycloartenol synthase 


\section{Loss of diversity:-}

According to World Health Organization (WHO), approximately $80 \%$ of world's population in developing countries depend on traditional medicines for primary healthcare (WHO, 2002) and in modern medicine too, nearly $25 \%$ are based on plant derived drugs (Tripathi, 2002). Habitat fragmentation and illegal trade from wild is considered one of the major factors for loss of plant number and diversity, and $P$. polyphylla is no exception with reckless and frequent removal; this directly affects plant dispersal, thus, reducing gene flow, increasing endogamy, and consequently disturbing the competitive capacity and adaptation of a species (Heywood et al., 2003, Oostermeijer et al., 2003). Therefore, due to high medicinal value, there has been large scale and unrestricted harvesting of the plant from the wild to meet its ever increasing demand for drug formulation by pharmaceuticals industries. The plant based rapid development of medicinal formulations in China resulted in increased illegal transportation from India has further led to reduction in natural populations of this species (Anonymous, 2002). Moreover, no such sustainable cultivation and attempts to replenish it in the wild have been reported.

Preserving the genetic diversity of species is one of the primary goals of conservation planning because long-term survival and evolution of species depend on the maintenance of sufficient genetic variability among populations to accommodate new selection pressures brought about by environmental changes (Barrett and Kohn, 1991). Population genetic diversity is affected by a number of factors including breeding system, seed dispersal, genetic drift, geographic range as well as the genetic isolation of populations and natural selection. P. polyphylla is an out crossing species that has nectarines and is entomophilous ( $\mathrm{Li}, 1$ 1998; Sage et al. 2001), and is considered to possess high population genetic diversity. Under natural conditions the plants grow as short-lived perennials, which defoliate in the winter and grow from rhizome in the following year. Besides above mentioned different anthropogenic and changing climatic conditions, the vulnerability of the plant is further aggravated by its characteristics nature such as long seed dormancy period of more than 2 years, poor germination, slow growth and annual fluctuations in the production of seeds ( $\mathrm{Li}, 1984 ; 1986$; Zhou et al. 2003). Of these various factors, breeding system is the primary factor that affects genetic diversity both among and within populations (Hamrick et al. 1990).

\section{Propagation, cultivation and market scenario:-}

Under natural conditions the plant propagates via seeds and rhizomes; these methods are well recognized method for multiplication and conservation of any endangered species. In addition, in vitro method can also be adopted for multiplication of this species as this technique has proven to be an alternate and effective means of rapid propagation that can facilitate the recovery of Rare Endangered Threatened (RET) Himalayan herbs (Chandra et al. 2006; Nadeem et al. 2000; Nandi et al. 2002; Pandey et al. 2004; Purohit et al. 2015). Recently, in vitro plant regeneration through direct somatic embryogenesis for this species as well as protocol using thin cell layer culture were developed (Raomai et al. 2014, 2015). Propagation by conventional as well as in vitro methods can be employed for mass scale multiplication of quality propagules for systematic cultivation in locations closer to their natural habitats (in alpine and sub-alpine areas) near village clusters. Keeping in view the applicability of the above mentioned methods it is desirable to apply simple methods like enhancing seed germination or propagation via rhizome segments, their hardening, acclimatization and subsequent field transfer. It must be emphasized that greater awareness needs to be created and the local inhabitants should be motivated to cultivate medicinal plants as an alternative source. In view of higher economic returns and commercial demand, cultivation packages need to be developed for the farmers. In order to implement such programmes effectively nurseries need to be established for supplying healthy and elite planting material. Non-government organizations, State Forest Departments, Village communities and voluntary bodies can be encouraged and suitably funded to undertake conservation (through cultivation) by planting clonally propagated as well as plants of seed origin in their natural habitat. Commercial cultivation of this species in India is yet to commence, although it is being practiced in China. Therefore, combined and sustained efforts with full participation of the local communities are required to reduce the pressure on natural populations. The plant is generally harvested in the senescence stage (October) because the yield of bioactive constituents is high at this time. It was found to be traded in bulk amount in the past to the cities in Nepal, namely, Pokhara and Kathmandu and presently in the different villages of Kumaun Region, Uttarakhand (India). It has been informed (following discussion with local inhabitants of Khati Village, Bageshwar, Uttarakhand) that species is being exported to neighbouring countries. Due to high price value of the rhizome along with increasing trade, villagers are now attracted towards collection of Paris polyphylla, a relatively easy option for livelihood. 


\section{Modern tools for conservation:-}

The physiological characters of the seeds along with habitat fragmentation are some of the reasons for low genetic diversity of the natural population of $P$. polyphylla. However, in the long run, it would be pertinent to conserve this species and reintroduce them in its natural habitat by the application of suitable methods. One such method is Ecological Niche Modelling, also popularly known as Species distribution modelling, is a recent tool which uses computer algorithms to generate predictive maps of species distributions in a geographic space by correlating the point distributional data with a set of environmental raster data. A study relating to the prediction of the ecological niche of $P$. polyphylla species across Western Himalayas (in Uttarakhand) needs to be undertaken using Maxent modelling approach as reported for other species (MaxEnt version 3.3.3e; Phillips et al., 2006). The different bioclimatic variables can be used to predict the potential distribution of $P$. polyphylla in the study area. Jackknife test will be used to evaluate the importance of the environmental variables for predictive modelling. Predictive distribution models aid in forecasting the spatial occurrence of species, especially habitat suitability or realized niche based on the data from field work in relation with climate and topographic factors (such as slope, elevation, and precipitation) (Pearson, 2007). The habitat suitability or niche prediction is done through various algorithms or principle which usually integrates the species occurrence information and environmental data to find out the possible favourable places. To obtain a continuous supply of plant material in vitro techniques can be used for multiplication and genetic improvement. It must be mentioned that at present a number of biotechnological approaches are being used for the conservation and improvement of plant species for desired traits.

The following areas of research on P. polyphylla have not been addressed so far and needs to be undertaken:

1. Quantitative assessment of geographical distribution and status of population using Ecological Niche Modelling.

2. Species-specific conservation plan and identify the bottlenecks that leads to the dispersal of plant from nature.

3. The morphological, biochemical and genetic diversity.

4. Standardization of plant propagation techniques (biotechnological and conventional) and scaling up production.

5. Development of suitable methods for reintroduction of the species in their natural habitat.

\section{Conclusion:-}

Biotechnological and ecological approaches are extremely important and essential for setting up of conservation and management step or plan for plant species that are mainly rare and endangered. Paris polyphylla is an economically and medicinally important species and is categorized as endangered (CAMP), and thus needs such approaches for its long term survival and sustainable utilization. Considering the ecological features and population status of this species, proper designing and implementation of effective conservation program need to be undertaken using Ecological Niche Modelling. The use of tissue culture (in vitro) biotechnological and conventional methods of multiplication for their reintroduction in natural habitats and niche areas of the species will be a significant initiative for its conservation. Since, the genus is important and has potential commercial application, hence immediate attention should be focused on its management, conservation and sustainable utilization. A thorough look of the summary of work depicted in Fig. 3 clearly reveals various studies already carried out and other areas that remain unattended. Furthermore, keeping in view the demand and status of this species, it is necessary to create awareness programmes for conservation, develop agro-technologies and conduct further research in order to overcome the problem being faced by this species. 


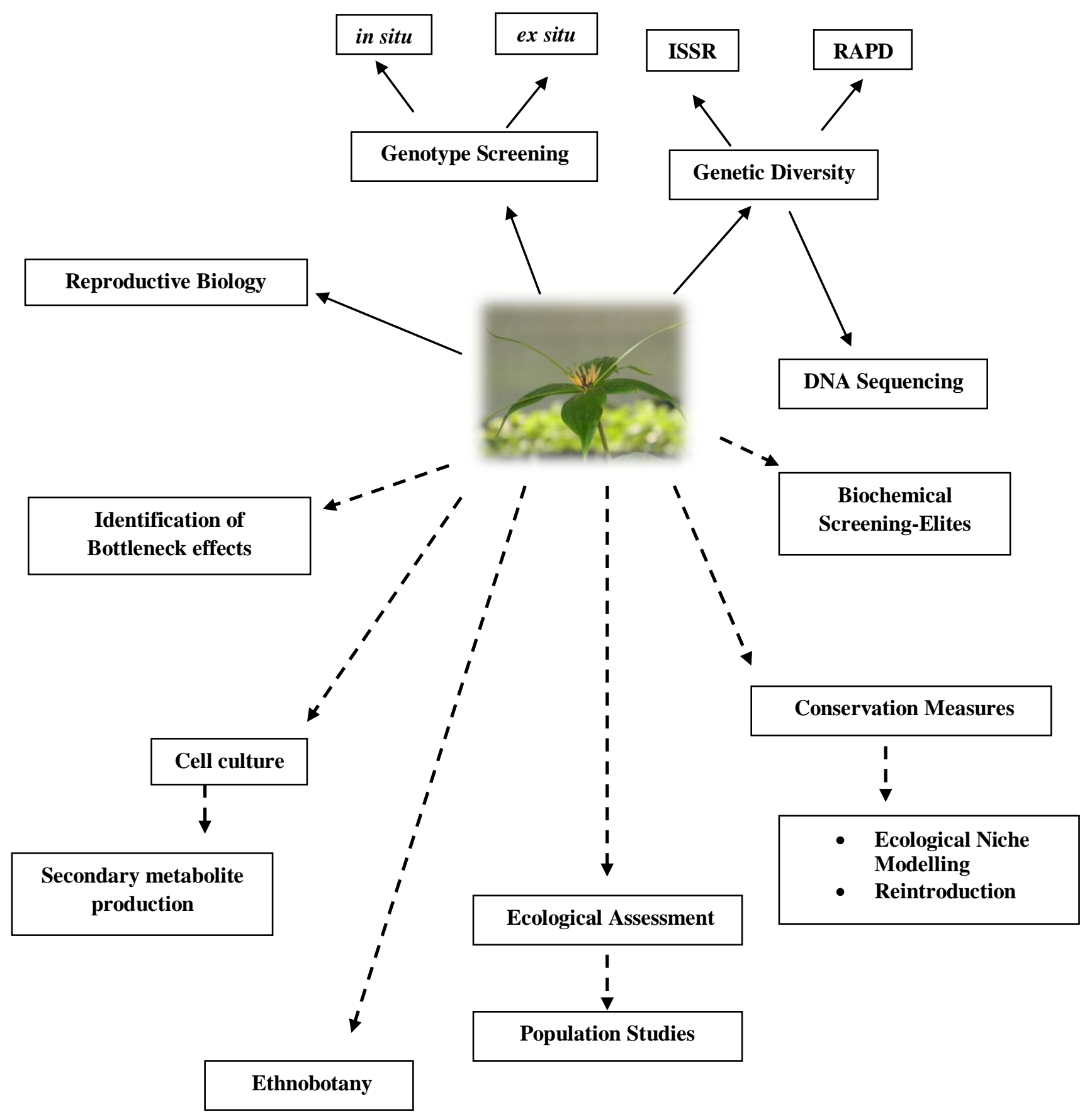

Fig.3:- Schematic representation of work carried out and lacking on Paris polyphylla. The continuous arrows indicate various studies already carried out, while discontinuous arrows indicate the gap area of works.

\section{Acknowledgement:-}

We would like to thank the Director of this Institute for encouragement and providing necessary facilities. This research is being supported by financial grant from Dept. of Biotechnology, Govt. of India, New Delhi, India through a research grant No. BT/Env./BC/01/2010 


\section{Conflicts of interest:-}

The author declares no conflicts of interest, financial, or other.

\section{References:-}

1. Anonymous, (2002): Newsfinder, 1-4.

2. Barrett, S.C.H. and Kohn, J.R. (1991): Genetic and evolutionary consequences of small population size in plants: implications for conservation. In: Falk DA, Holsinger KE, editors. Genetics and conservation of rare plants. New York: Oxford University Press; 3-30

3. Bhattarai, K.R. and Ghimire, M.D. (2006): Cultivation and sustainable harvesting of commercially important medicinal and aromatic plants of Nepal. Heritage Research and Development Forum, Nepal, pp.369-372.

4. CAMP, (2003): Conservation assessment and management prioritization for the medicinal plants of Himachal Pradesh, Jammu \& Kashmir and Uttarakhand. In: Proceedings of the workshop held at Shimla, Hosted by Foundation for Revitalisation of local Health Traditions (FRLHT), Bangalore, India.

5. Chandra, B., Palni, L.M.S. and Nandi, S.K. (2006): Propagation and conservation of Picrorhiza kurrooa Royle ex Benth: an endangered Himalayan medicinal herb commercial value. Biodiversity and Conservation; 15: 2325-2338

6. Deng, D.W., Lauren, D.R., Cooney, J.M., Jensen, D.J., Wurms, K.V., Upritchard, J.E., Cannon, R.D., Wang, M.Z. and Li, M. Z. (2008): Antifungal saponins from Paris polyphylla Smith. Planta Medica; 74:1397-1402

7. Devkota, K. P. (2005): Bioprospecting studies on Sarcococca hookeriana Bail, Sonchus wightianus DC, Paris polyphylla Smith and related Medicinal Herbs of Nepal: Ph. D Thesis, HEJ Research Institute of Chemistry, International Centre for Chemical Science, University of Karachi, Karachi-75270, Pakistan

8. Devkota, K.P., Tareq, H. K. M., Ranjit, R., Lannang, A. M., Samreen and Iqbal C.M. (2007): Tyrosinase inhibitory and anti-leishmanial constituents from the rhizomes of Paris polyphylla. Natural Product Research; 21:321-327

9. Djerassi, C., Rosenkranz, G., Pataki, J. and Kaufmann, S. (1952): Steroids, XXVII. Synthesis of allopregnane3 , 11 beta, 17-, 20 , 21-pentol from cortisone and diosgenin. Journal of Biological Chemistry. 194:115-118.

10. Fu, Y.L., Yu, Z.Y., Tang, X. M., Zhao, Y., Yuan, X. L., Wang, S., Ma, B. P. and Cong, Y.W. (2008): Pennogenin glycosides with a spirostanol structure are strong platelet agonists: structural requirement for activity and mode of platelet agonist synergism. Journal of Thrombosis and Haemostasis; 6:524-533

11. Grey, C. H. (1938): Hardy Bulbs. Williams \& Norgate

12. Hamrick, J.L., Godt, M. J. W. (1990): Allozyme diversity in plant species. In: Brown ADH, Clegg MT, Kahler AL, Weir BS, editors. Plant population genetics, breeding and genetics resources. Sunderland: Sinauer: 43-63

13. Heywood, V.H. and Iriondo, J. M. (2003): Review: Plant conservation: old problems, new perspectives. Biological Conservation; 113:321-335

14. Huxley, A. (1992): The New RHS Dictionary of Gardening. MacMillan Press.

15. IUCN, Nepal. (2004): National Register of Medicinal and Aromatic plants (Revised and updated). IUCN- The World Conservation Union, Kathmandu, Nepal.Xiii+202PP

16. Lee, M.S., Yuet-Wa, J.C., Kong, S.K., Yu, B., Eng-Choon, V.O., Nai-Ching, H.W., Chung-Wai, T.M. and Fung, K.P. (2005): Effects of polyphyllin D, a steroidal saponin in Paris polyphylla, in growth inhibition of human breast cancer cells and in xenograft. Cancer Biology and Therapy; 4:1248-1254

17. Li, H. (1984): The phylogeny of the genus Paris L. Acta Botanica Yunnanica; 6:351-362

18. Li, H. (1998): The genus Paris (Trilliaceae). Beijing: Science press

19. Li, Y. C. (1986): Vegetative propagation of Paris polyphylla var. yunnanensis. Acta Botanica Yunnanica; 8:429-435 (in Chinese)

20. Nadeem, M., Palni, L.M.S, Purohit, A.N., Pandey, H. and Nandi, S.K. (2000): Propagation and conservation of Podophyllum hexandrum Royle: an important medicinal herb. Biological Conservation; 92:121-129

21. Nandi, S.K., Palni, L.M.S. and Kumar, A. (2002): Role of Plant Tissue Culture in Biodiversity and Economic Development. Himavikas Occasional Publication No-15. Gyanodaya Prakashan. Nainital, ISBN: 81-85097-55-0

22. Man, S., Gao, W., Zhang, Y., Yan, L., Ma, C., Liuc, C. and Huang, L. (2009): Antitumor and anti-metastatic activities of Rhizoma Paridis saponins. Steroids; 74:1051-1056

23. Oostermeijer, J.G.B., Luijten, S.H., den, Nijs J.C.M. (2003): Integrating demographic and genetic approaches in plant conservation. Biological Conservation; 113:389-398

24. Pandey, H., Nandi, S.K., Kumar, A., Palni, U.T., Chandra, B. and Palni, L.M.S. (2004): In vitro propagation of Aconitum balfourii Stapf: an important aconite of the Himalayan alpines. Journal of Horticulture Science \& Biotechnology; 79:34-41 
25. Paul, A., Gajurel, P.R. and Das, A.K. (2015): Threat and conservation of Paris polyphylla an endangered, highly exploited medicinal plant in the Indian Himalayan Region. Biodiversitas; 16 (2): 295-302

26. Pearson, R.G. (2007): Species distribution modelling for conservation educators and practitioners. Synthesis. American museum of Natural History. Available at http://ncep.amnh.org

27. Phillips, R. and Rix, M. (1989): Annuals and Biennials: The Garden Plant Series. MacMillan Press

28. Phillips, S.J., Anderson, R.P. and Schapire, R.E. (2006): Maximum entropy modeling of species geographic distributions. Ecological Modelling; 190:231-259

29. Purohit, S., Rawat, V., Jugran, A.K., Singh, R.V., Bhatt, I.D. and Nandi, S.K. (2015): Micro propagation and genetic fidelity analysis in Valeriana jatamansi Jones. Journal of Applied Research on Medicinal and Aromatic Plants; 2:15-20

30. Rawat, V.S., Rawat, Y.S. and Shah, S. (2010): Indigenous knowledge and sustainable development in the Tones Valley of Garhwal Himalaya. Journal of Medicinal Plants Research; 4(19):2043-2047

31. Raomai, S., Kumaria, S., Tandon., P. (2014): Plant regeneration through direct somatic embryogenesis from immature zygotic embryos of the medicinal plant, Paris polyphylla Sm. Plant Cell, Tissue and Organ Culture; $118: 445-455$

32. Raomai, S., Kumaria, S., Kehie., M. and Tandon., P. (2015): Plantlet regeneration of Paris polyphylla Sm. via thin cell layer culture and enhancement of steroidal saponins in mini-rhizome cultures using elicitors. Plant Growth Regulation; 75:341-353

33. Rastogi, P. and Mehrotra, B.N. (1993): Compendium of Indian Medicinal Plants. (New Delhi, India: National Institute of Science and Communication), pp. 479-480.

34. Sage, T.L., Griffin, S., Pontieri, V., Drovac, P., Cole, W.W. and Barrett, S.C.H. (2001): Stigmatic selfincompatibility and mating patterns in Trillium grandiflorum and Trillium erectum (Melanthiaceae). Annals of Botany; 88:829-841

35. Sun, J., Liu, B.R., Hu, W.J., Yu, L.X. and Qian, X.P. (2007): In vitro anticancer activity of aqueous extracts and ethanol extracts of fifteen traditional Chinese medicines on human digestive tumor cell lines. Phytotherapy Research; 21:1102-1104

36. Thomas, G.S. (1990): Perennial Garden Plants. J. M. Dent \& Sons.

37. Tripathi, G. (2002): Indigenous Knowledge and Traditional Practices of Some Himalayan Medicinal Plants. In: Samant SS, Dhar D, Palni LMS (eds) Himalayan Medicinal Plants Potential and Prospects, Gyanodaya Prakashan, Nainital, pg. 151-156

38. Wang, G.X., Han, J., Zhao, L.W., Jiang, D.X., Liu, Y.T. and Liu, X.L. (2010): Antihelmintic activity of steroidal saponins from Paris polyphylla. Phytomedicine; 17:1102-1105

39. Wang, Y., Gao, W.Y. and Yuan, L.C. (2007): Chemical constituents from rhizome of Paris polyphylla var yunnanensis. Chinese Traditional and Herbal Drugs; 38:17-20 (In Chinese)

40. Wei, J.C., Gao, W.Y., Yan, X.D., Wang, Y., Jing, S.S. and Xiao, P.G. (2014): Chemical constituents of plants from the Genus Paris. Chemistry and Biodiversity; 11: 1277-1297.

41. World Health Organization (2002): Traditional Medicine Strategy 2002-2005. World Health Organization, Geneva

42. Wu, S.S., Gao, W.Y., Duan, H.Q. and Jia, W. (2004): Advances in studies on chemical constituents and pharmacological activities of Rhizoma paridis. Chinese Traditional and Herbal Drugs; 35:344-347

43. Zhou, L.G., Wu, J.Y. and Wang, S.L. (2003): Low-temperature stratification strategies and growth regulators for rapid induction of Paris polyphylla var; yunnanesis seed germination. Plant growth Regulation; 41:179-183 